\title{
Working From Home Facilities Model During Pandemic Situation
}

\author{
Irwan Mohammad Ali ${ }^{1}$, MdYusof Hamid ${ }^{2}$, MohdAzian Zaidi ${ }^{3}$, Wan SamsulZamani Wan Hamdan ${ }^{4}$, \\ Nor Amin Mohd Radzuan 5
}

1,2,3,4,5 Faculty of Architecture, Planning and Surveying, Universiti Teknologi MARA,

Perak Branch, Seri Iskandar Campus, Seri Iskandar, 32610 Perak, Malaysia.

irwan9471@uitm.edu.my ${ }^{1}$

Article History: Received: 10 November 2020; Revised: 12 January 2021; Accepted: 27January 2021;

Published online: 05April 2021

\begin{abstract}
Since WHO declare COVID-19 as a pandemic, it has changed the way of our life today. Mostly, all countries in the world implementing lockdown or movement control to stop the spreading. In Malaysia, the government announced a Movement Control Order (MCO) which requires the closure of all businesses except those providing essential services and items. This affects most business operations and companies have to switch to Working From Home (WFH). This paper aim to propose WFH Facilities Model during a pandemic (COVID-19). The scope of this study pertains to Malaysian citizens. The main methods used in this research were a deductive approach that suit to cross-sectional research. This research employs a simple random sampling technique to achieve the required minimum sample size. Therefore, to gather data, a questionnaire survey technique was selected.Meanwhile, using the SmartPLS3, structural equation modeling (SEM) technique was used to test the research hypotheses. A total of 500 questionnaires was circulated via a web-based self-administered questionnaire using the Google Forms survey. Out of 500 questionnaires distributed, only 363 sets were replied to and completed with a high response rate of up to $73 \%$. The findings of the study show that from six research hypotheses, only two hypotheses are supported which are Work-Family Related (WF) and Modern Technology (MT).Hence, this study recommends that it is important for any organisation that wants to implement WFH to pay an attention to both attributes.
\end{abstract}

Keywords: Working From Home, Working Facilities, Movement Control Order, Model, Pandemic COVID-19

\section{Introduction}

The spreading of COVID-19 has caused shock to the world's economy and devastating human toll. The Emergency Committee of the World Health Organization (WHO) declared a global health emergency based on increasing case-reported rates in China and globally.(Velavan \& Meyer, 2020).Furthermore, the WHO announcedCOVID-19 as a global pandemic on 11 March 2020 (Shah et al., 2020). Until October 2020, COVID19 has spread to numerous different countries and now in the third wave. Most countries have implemented extreme lockdown, movement control, or shelter orders on their residents in an attempt to reduce the outbreak of COVID-19. The spread of COVID-19 was greatly mitigated in China by the drastic prevention strategies enforced(Kraemer et al., 2020). Consequently, the success of these preventive measures is therefore highly dependent on the cooperation and compliance of all members of society as a whole (Azlan et al., 2020). The response of most countries involves contact tracking, self-isolation or quarantine, the promotion of public health initiatives, the improvement of health services, the strengthening of health facilities, and the postponement or cancellation of large-scale public events(Bedford et al., 2020).Hence, most businesses, therefore, introduce flexible working structures such as teleworking, distance learning, crowd limitation and avoidance, closure of non-critical facilities and services (WHO, 2020). These initiatives ensure a physical distance between individuals and minimize interaction with polluted surfaces, while at the same time fostering and preserving virtual social interactions within families and communities. This approach is also known as Working From Home (WFH). WFH could potentially become a norm for many businesses following the pandemic situation. WFH means an employee is working from their space (house, apartment, or place of residence), rather than working from the office either full-time or when it's most convenient for them.

It is observable during the COVID-19 pandemic that the workforce and the way of working are shifting dramatically and expected to expand(Ahmadi et al., 2000; Montenovo et al., 2020). Most working sector, including management, professional and related occupations were more likely to shift toward WFH (Brynjolfsson et al., 2020). This transition might serve as the catalyst for a new way of doing business for years to come (Deng et al., 2020). It is no doubt that WFH led to a $13 \%$ performance increase, improved employer satisfaction, and their attrition rate halved. This shows the advantages of learning and selection effects when new management approaches like WFH are introduced (Bloom et al., 2015).In WFH, the notion of work transformation, the convergence of people, space, and technology with a direct emphasis on business operations is crucial. WFH's ultimate aim is to help businesses break out of their conventional job description and shift to a more agile, inspiring, communicating, and satisfying environment Work transformation offers the ability for groups of facilities to play a crucial strategic role in serving the rapidly evolving environment and providing the business with real strategic value-added. In terms of the real office and the rapidly growing virtual office, work 
transition is focused on facilities management, human resources, and information technology, all working together to create more innovative ways of managing space (Hassanain, 2006; Robertson, 2000).Thus, in the case of WFH, the provision of services should ensure facility functionality like effective virtual connectivity and accessibility (Kojo \& Nenonen, 2015).

\section{Research Conceptual Model and Hypotheses}

Primarily, based on the theory of planned behaviour ( TPB), a research conceptual model was developed. The most prominent social psychological model for understanding and predicting human behaviour in particular contexts (Ajzen, 2001). The TPB is defined as an individual's intention to perform a given behaviour and is generally assumed to capture the motivational factors that determine individual behaviours, such as effort and willingness to perform a behaviour.This research conceptual model was established on the basis of six determining factors identified by the authors in the previous research.The six determinant factors for WFH Facilities consists of Work-Family Related (WF); Organisational Support (OS); Working Culture (WC); Job Autonomy (JA); Modern Technology; and Social Media (SM).

The first determinant factor is Work-Family Related (WF). It can be interpreted as the fulfillment of rolerelated expectations that are accepted and shared in the work and family environments between a person and his or her partners (Grzywacz \& Carlson, 2007). The WFitemsincludedmanaging work obligations, doing jobs while relaxing at home, emotional support fromfamily,isolateworkand family priority, and resisting lifestyle with the current situation. In line withNoor (2003) study, these WFitems were expected to be related to work-family conflict and well-being during the pandemic COVID-19.

Secondly, the determinant factors of Organisational Support (OS) can be described as the beliefs of employees about the degree to which the company values its commitment and cares about its well-being (Eisenberger et al., 2004; Satardien et al., 2019). The OS itemsincludedemployer understanding, assisting withfamily-friendly, responsive,improveskills and on-job training,treatedwithtrust and respect. Hence, support of the organisation is essential for employees' to perform according to the transforming work environment(Halcomb et al., 2020).

The third determinant factor is Working Culture (WC)that can be defined as a set of informal norm values and norms. The WC control the way people or groups in an organisation interact with eachotherinsideand outside the organisation(Akbar et al., 2019).The WC items included working extra time, two-way communication, regular feedback,positiveenvironment,flexible location to do jobs, andsufficient workloadto do.Apart from that, WC isanticipatedto generates values and beliefs in the organisation(Ali et al., 2019),definitelyduringpandemic COVID-19.

The fourth determinant factor is Job Autonomy (JA). JA can be identified as the degree to which the job offers the employee considerable freedom, independence, and discretion in scheduling the work and in specifying the procedures to be used in carrying it out (De Spiegelaere et al., 2016).JA can be divided into two main dimensions: work schedule (with the autonomy to schedule the task) and work procedures (with the autonomy to choose strategy) (Khoshnaw \& Alavi, 2020). The JA items included precise job criterion, detail work procedure, sufficienttimeframe,input in decision-making, and personal initiative.Inadvanced, JA improvedtheeffect ofbalancedemotionon employee voice, which, in turn, enhanced the mediated relationship between empowering leadership and employee voice via harmoniouspassion(Gao \& Jiang, 2019).

The next determining factors are the needs of Modern Technology (MT), which is identified by the ability to automate business processes and present information sufficiently (Beliaeva \& Chernyavskaya, 2019). The way people live has definitely been changed by technology. It has influenced numerous aspects of life and redefined life (Raja \& Nagasubramani, 2018).The MT items included surveillancecamera, video and audiorecordings,internet network, supporting computer devices, mobile gadgets, and work-related mobile applications. During pandemic COVID-19, the modern technology has contributed in improving people's lives (Kumar et al., 2020).

Lastly, the determinant factor of Social Media (SM) can be defined as a series of technological innovations in both hardware and software that facilitate inexpensive content creation, interaction, and interoperability for creative online users(Berthon et al., 2012; Wang \& Kim, 2017). TheSM variables that contribute to job performanceincludedFacebook,Instagram, WhatsApp, YouTube, Google Scholar, andResearchGate.During the ongoing COVID-19 outbreak, individuals operating on the SM were able to obtain and share various types of data on a wide and extraordinary scale (Li et al., 2020). 
In particular, all the six determinant factors are included in the research conceptual model. This research conceptual model consists of 34 items for independent variables and five items for dependent variables. Hence, six hypotheses were established based on the research conceptual model, as shown in Figure 1.

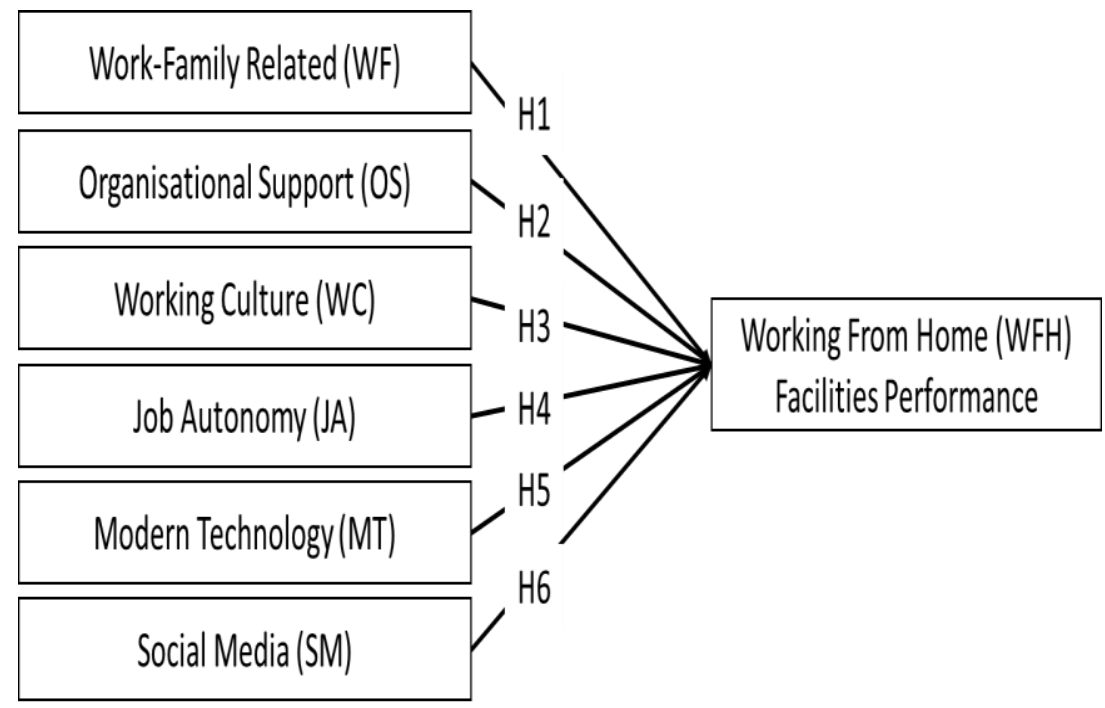

Figure 1. Research Conceptual Model

H1: There is a significant relationship between the determinant factor of the Work-Related Family for WFH performance during a pandemic situation.

H2: There is a significant relationship between the determinant factor oftheOrganisational SupportforWFH performance during a pandemic situation.

H3: There is a significant relationship between the determinant factor of the Working Culture for WFH performance during a pandemic situation.

H4: There is a significant relationship between the determinant factor of the Job Autonomy for WFH performance during a pandemic situation.

H5: There is a significant relationship between the determinant factor of the Modern Technology for WFH performance during a pandemic situation.

H6: There is a significant relationship between the determinant factor of the Social Media for WFH performance during a pandemic situation.

\section{Methods}

The primary methods used in this research were a deductive approach that suit to cross-sectional research. This research employs a simple random sampling technique to achieve the required minimum sample size for a questionnaire survey technique to collect data. Meanwhile, the structural equation modeling (SEM) approach was used to test the research hypotheses using the SmartPLS 3 software.The analysis was carried out in two stages: i) the measurement model assessment, and ii) the structural model assessment. The measurement model assessment involved examining the adequacy of the model by analysing the relationships between each determinant factor and items in independent and dependent variables. Meanwhile, the structural model assessment is the part that associateswith independent and dependent variables.After satisfying the prerequisites of measurement model assessment have to proceed with the evaluation of thestructuralmodelforthe collinearityissue.In addition, all the threshold values for every criterion were clearly represented under the conclusion to have a comprehensive understanding of the evaluation of measurement and structural model.

The sufficient sample size from the local population was properly identified using a simple random sampling technique. The simple random sampling technique is a popular type of random or prospect sampling ( $\mathrm{Al} \mathrm{Ghayab}$ et al., 2016; Gupta \& Shabbir, 2008). In this technique, each sample of the population has the same chance of being selected as a subject. The sampling unit of analysis for this research was a Malaysian citizen. Therefore, 
the minimum sample size for this research is between 271 for a $90 \%$ confidence level with a $5 \%$ confidence interval (error margin); and 385 for a 95\% confidence level with a 5\% confidence interval.A total of 500 questionnaires was circulated via a web-based self-administered questionnaire using the Google Forms survey. Out of 500 questionnaires distributed, only 363 sets were replied to and completed with a high response rate of up to $73 \%$. The findings of the study show that from six research hypotheses, only two hypotheses are supported which are Work-Family Related (WF) and Modern Technology (MT). Hence, this study recommends that it is important for any organisation that wants to implement WFH to pay an attention to both attributes.

\section{Demographic Data}

Throughout the simple random technique, potential respondents were randomly identified and invited to take part in this study. Then, the frequency descriptive analysis was carried out to attain the demographic profile of the respondents who answered the questionnaire. The demographic data consists of several categories such as age, gender, academic qualification, occupation, and time allocation for WFH of the respondent.The questionnaires were answered by respondents who are WFH during the COVID-19 MCO. A total of 500 questionnaires was distributed via a web-based self-administered questionnaire. Out of 500 questionnaires distributed, only 363 sets were replied to and completed. This clearly shows the response rate is $73 \%$, which is considered high responses.

A detailed overview of the demographic profiles of the respondents is presented in Table 1. Based on the response, most of the respondents are from the age group of 21 to 30 years old (43.3\%) and 31 to 40 years old $(37.5 \%)$, and minimal respondents within the range of 41 to 50 years old group (16\%). Male respondents slightly outnumber female respondents, total numbers of 54.6 percent as against 45.5 percent, respectively. The majority of the respondents have a Master's Degree with 106 respondents (29.5\%), followed by Bachelor's Degree with 96 respondents (26.4\%), SPM/STPM/Certificate with 56 respondents (15.4\%), and Ph.D. with 53 respondents (14.6) as their highest educational qualification. In terms of occupation, the questionnaire was mostly answered by the government servants with a total of 130 respondents $(35.8 \%)$. Then followed by internship students (including the SLIM program) and from the private sector with 111 respondents (30.6\%) and 106 respondents (29.2\%), respectively. In general, the allocation time for WFH shows most of the respondents spent time within 4 to 12 hours daily. Specifically, 4 to 8 hours and 8 to 12 hours are highly rated with 185 respondents (51\%) and 131 respondents $(36.1 \%)$, respectively.

Table 1.Respondent profile

\begin{tabular}{|c|c|c|c|c|}
\hline \multirow{2}{*}{ Category } & \multirow{2}{*}{ Indicator } & Frequen & \multirow{2}{*}{$\begin{array}{l}\text { Valid } \\
\text { Percent }\end{array}$} & \multirow{2}{*}{$\begin{array}{l}\text { Cumulative } \\
\text { Percent }\end{array}$} \\
\hline & & cy & & \\
\hline \multirow{6}{*}{ AGE } & 21 - 30 years old & 157 & 43.3 & 43.3 \\
\hline & $31-40$ years old & 136 & 37.5 & 80.7 \\
\hline & $41-50$ years old & 58 & 16.0 & 96.7 \\
\hline & $51-60$ years old & 10 & 2.8 & 99.4 \\
\hline & Over 61 years old & 2 & 0.6 & 100.0 \\
\hline & Total & 363 & 100.0 & \\
\hline \multirow{3}{*}{ GENDER } & Male & 165 & 45.5 & 45.5 \\
\hline & Female & 198 & 54.5 & 100.0 \\
\hline & Total & 363 & 100.0 & \\
\hline \multirow{6}{*}{ ACADEMIC } & SPM/STPM/Certificate & 56 & 15.4 & 15.4 \\
\hline & Diploma & 51 & 14.0 & 29.5 \\
\hline & Bachelor Degree & 96 & 26.4 & 55.9 \\
\hline & Master & 107 & 29.5 & 85.4 \\
\hline & $\mathrm{PhD}$ & 53 & 14.6 & 100.0 \\
\hline & Total & 363 & 100.0 & \\
\hline \multirow{4}{*}{ OCCUPATION } & Student & 111 & 30.6 & 30.6 \\
\hline & Government Sector & 130 & 35.8 & 66.4 \\
\hline & Private Sector & 106 & 29.2 & 95.6 \\
\hline & Business & 16 & 4.4 & 100.0 \\
\hline
\end{tabular}




\begin{tabular}{lllll} 
& Total & 363 & 100.0 & \\
\hline & $1-4$ hours & 1 & 0.3 & 0.3 \\
& $4-8$ hours & 185 & 51.0 & 51.2 \\
\multirow{2}{*}{ TIME WFH } & $8-12$ hours & 131 & 36.1 & 87.3 \\
& $12-16$ hours & 36 & 9.9 & 97.2 \\
& More than 16 hours & 10 & 2.8 & 100.0 \\
& Total & 363 & 100.0 & \\
\hline
\end{tabular}

\section{Results and Findings}

\section{Structural Equation Modelling}

Structural Equation Modelling (SEM) is the analysis technique used in this research, which is a multivariate analysis technique based on the ideas used in regression analysis that overcomes important and statistical problems with more traditional approaches. In this analysis, there are two assessments conducted: measurement model assessments and structural model assessment.

\section{Measurement Model Assessment}

To provide rigorous testing of the reliability and validity of the research model, the evaluation of the measurement model is important. It is also used for latent constructs and their manifest variables to be evaluated (Loehlin, 1998). For the evaluation of the measurement model, several steps were used in this analysis, including the evaluation of convergent validity and discriminant validity for independent and dependent variables.The summary of the indicator loadings shown in Table 2.The first attempt to establish a measurement model indicates that indicator loading for WC1 and MT1 are lower thanthe0.6 cut-off thresholdvalue. Therefore, these two items were removed and reassess all retained indicator loadings. The second attempt indicates that all indicatorloadings were greater than 0.60 and indicator loadings ranged from 0.67 to 0.92 . Items withindicator loadings exceed 0.60 were considered high significant (Hair et al., 2010). High indicator loadings indicate that measurements had convergent validity.

Table 2.Indicator loading

\begin{tabular}{lll}
\hline Items & 1 & 2 \\
\hline WF1 & 0.778372 & 0.778382 \\
WF2 & 0.846690 & 0.846688 \\
WF3 & 0.850404 & 0.850396 \\
WF4 & 0.775217 & 0.775219 \\
WF5 & 0.836070 & 0.836065 \\
WF6 & 0.806724 & 0.806731 \\
OS1 & 0.906462 & 0.906449 \\
OS2 & 0.920936 & 0.920929 \\
OS3 & 0.920624 & 0.920617 \\
OS4 & 0.719226 & 0.719258 \\
OS5 & 0.865296 & 0.865298 \\
WC1 & 0.025009 & Item Removed \\
WC2 & 0.802643 & 0.800475 \\
WC3 & 0.825490 & 0.826398 \\
WC4 & 0.865200 & 0.869502 \\
WC5 & 0.746088 & 0.748868 \\
WC6 & 0.769516 & 0.771781 \\
JA1 & 0.802785 & 0.802785 \\
JA2 & 0.794830 & 0.794830 \\
JA3 & 0.817941 & 0.817927
\end{tabular}


Irwan Mohammad Ali, Md Yusof Hamid, Mohd AzianZaidi, Wan SamsulZamani Wan Hamdan, Nor Amin Mohd Radzuan

\begin{tabular}{lll}
\hline JA4 & 0.802557 & 0.802559 \\
JA5 & 0.797488 & 0.797500 \\
MT1 & 0.463370 & Item Removed \\
MT2 & 0.679930 & 0.676956 \\
MT3 & 0.862951 & 0.864865 \\
MT4 & 0.916256 & 0.921003 \\
MT5 & 0.892374 & 0.900202 \\
MT6 & 0.811424 & 0.819370 \\
SM1 & 0.739817 & 0.739885 \\
SM2 & 0.719295 & 0.719376 \\
SM3 & 0.748805 & 0.748729 \\
SM4 & 0.744402 & 0.744398 \\
SM5 & 0.740080 & 0.740051 \\
SM6 & 0.711402 & 0.711403 \\
BF1 & 0.716842 & 0.717067 \\
BF2 & 0.791390 & 0.791457 \\
BF3 & 0.850294 & 0.849952 \\
BF4 & 0.843673 & 0.843460 \\
BF5 & 0.679558 & 0.679995 \\
\hline
\end{tabular}

Table 3.Internal consistency reliability \& convergent validity

\begin{tabular}{lccr}
\hline & Cronbach's Alpha & Composite Reliability & AVE \\
\hline Working From Home Facilities & 0.836407 & 0.884740 & 0.607365 \\
Work-Family Related & 0.899763 & 0.922800 & 0.666119 \\
Organisation Support & 0.917542 & 0.939131 & 0.756674 \\
Social Media & 0.835961 & 0.875157 & 0.538904 \\
Working Culture & 0.862967 & 0.901464 & 0.647236 \\
Job Autonomy & 0.862608 & 0.900855 & 0.645066 \\
Modern Technology & 0.893639 & 0.922782 & 0.707248 \\
\hline
\end{tabular}

In order to established internal consistency reliability and convergent validity, all construct factor loadings and AVE must exceed the acceptable 0.5 cut-off threshold value(Hair et al., 2010). In this research, the AVE was exceeding the 0.5 cut-off threshold value and considered satisfactory(refer to Table 3).Every variable/item was found to have great convergent validity based on good composite reliability $(>0.8)$; thus, based on results in Table 3, the study's measurement model demonstrated high satisfactory convergent validity.

The evaluation of discriminant validity is the next step in the validation process of the construct. Discriminate validity was assessed here by analyzing the cross-loads of each construct item and the measured square root of AVE for each construct. On their corresponding construct, all objects should have higher loading than crossloading on other constructs in the model. For all factors, the square root of AVE should be larger than all the correlations between that construct and other constructs. Table 4 indicates that the AVE (in bold in Table 4) diagonal values is greater than the AVE off-diagonal values. Hence, discriminant validity was established by the test.

Table 4.Discriminate Validity

\begin{tabular}{lll}
\hline & AVE & \\
\hline Working From Home Facilities & 0.60737 & $\mathbf{0 . 7 7 6 3 9}$ \\
Work-Family Related & 0.66612 & $\mathbf{0 . 8 1 5 5 8}$ \\
Organisation Support & 0.75667 & $\mathbf{0 . 8 6 6 5 1}$ \\
Social Media & 0.53890 & $\mathbf{0 . 7 3 3 9 7}$ \\
Working Culture & 0.64724 & $\mathbf{0 . 8 0 3 4 0}$ \\
Job Autonomy & 0.64507 & $\mathbf{0 . 8 0 3 1 2}$ \\
Modern Technology & 0.70725 & $\mathbf{0 . 8 3 6 4 8}$ \\
\hline
\end{tabular}




\section{Structural Model Assessment}

The next step in the process is to assess the path coefficient of all items by comparing beta $(\beta)$ values among all paths. The path coefficient represents hypothesized relationships between WFH facilities determinants on WFH performance.The highest $\beta$ value indicates the strongest impact of WFH facilities determinants (independent variables) on WFH performance (dependent variables). According to Hair et al. (2014), path coefficients should exceed 0.10 to account for a certain impact within a model. However, the $\beta$ value must be tested for its significance level through the t-value test, carried out by performing a non-parametric bootstrapping technique (Chin, 1998).Therefore, to test the statistical significance of each path coefficient, a bootstrap resampling procedure has been used. The number of resample iterations for this research was 5,000 to generate a stable estimation, as suggested by Henseler et al. (2016).

Table 5.Hypotheses Result

\begin{tabular}{|c|c|c|c|}
\hline & $\begin{array}{l}\text { Path } \\
\text { Coefficient }(\beta)\end{array}$ & t-value & Remarks \\
\hline 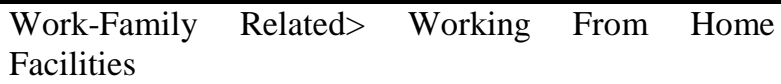 & 0.32404 & $3.18176 * * *$ & Supported \\
\hline Organisation Support> Working From Home Facilities & 0.02964 & 0.25753 & Not Supported \\
\hline Social Media $>$ Working From Home Facilities & 0.01565 & 0.17828 & Not Supported \\
\hline Working Culture $>$ Working From Home Facilities & 0.12050 & 0.89986 & Not Supported \\
\hline Job Autonomy $>$ Working From Home Facilities & 0.10481 & 0.96079 & Not Supported \\
\hline Modern Technology > Working From Home Facilities & 0.33630 & $2.97559 * * *$ & Supported \\
\hline
\end{tabular}

Results from Table 5 show that most of the $\beta$ values are exceeding the cut-off point value of 0.01 for all items, as suggested by Hair et al. (2014). The highest $\beta$ value ofWFHfacilitiesdeterminants which indicates the most significant impacts on WFH performance.The highest $\beta$ resultswere0.336 for modern technology. Meanwhile, the lowest $\beta$ results were 0.016 for social media. According to Hair et al. (2014), it is suggested that acceptable t-values for a two-tailed test is 1.64 (significance level $=0.10$ or $10 \%$ ), 1.96 (significance level $=0.05$ or $5 \%$ ) and 2.58 (significance level $=0.01$ or $1 \%$ ). Hence, the t-values ofmodern technology and work-family related were 2.976 and 3.182, respectively. Itshowshigher than minimum cut-off significance values, which were at least 0.01 or $1 \%$.This indicates that both factors of Work-Family Relatedand Modern Technology have a significant relationshipto the WFHperformanceof this research.The other determinants which areSocial Media, Organisation Support, Working Culture, and Job Autonomy had a smaller amount of significant relationships on WFH performance, respectively. 


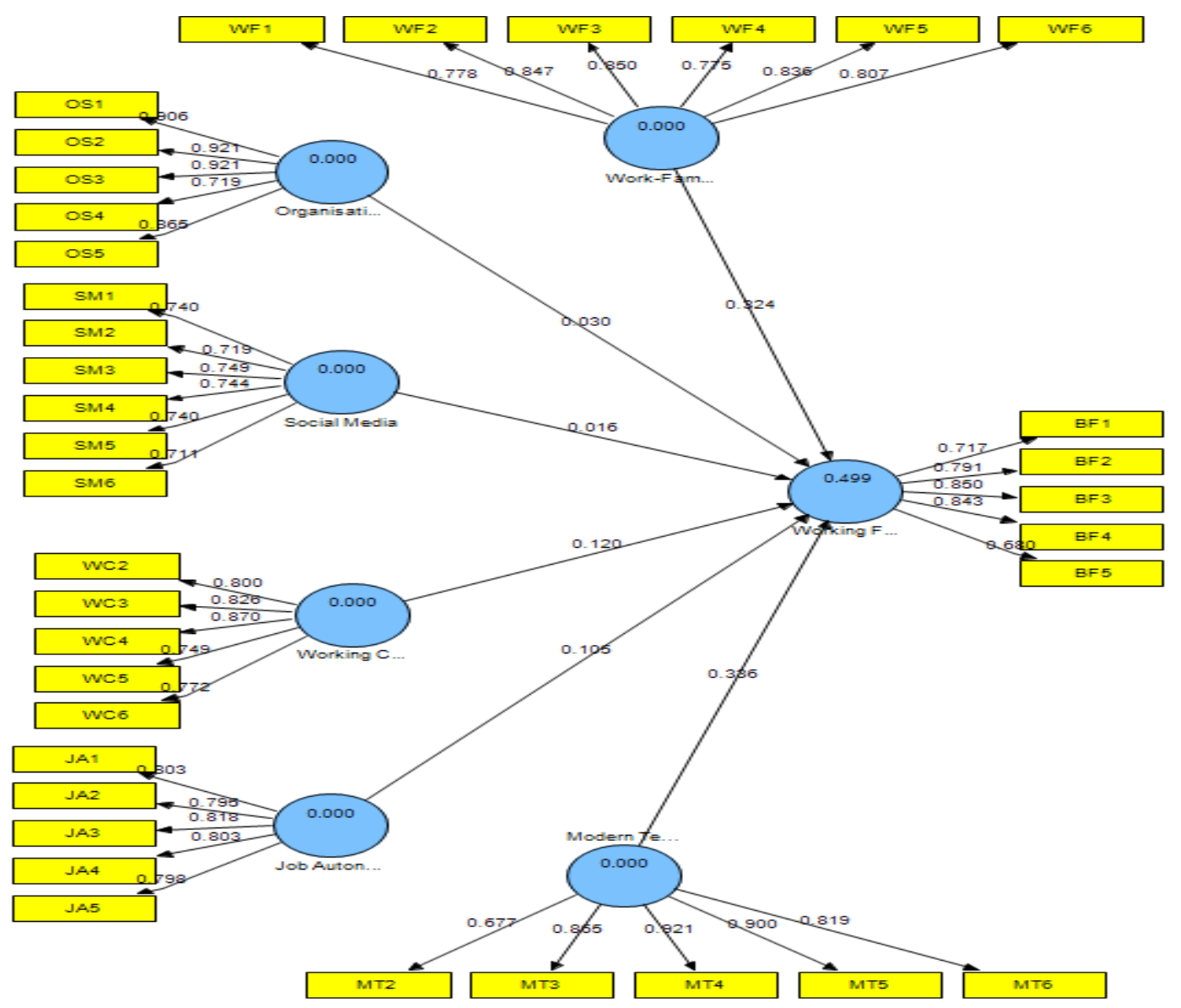

\section{Conclusion}

The global spread of COVID-19 is keeping people at home. Most employers are encouraging or requiring their employees to WFH for an indeterminate amount of time. This situation gives big impacts on business operations for most organisations. Therefore, organisation members that remote to the WFH lifestyle need to change their habits, routines and surely supporting facilities to make WFH a success. In this study, the significant relationship of WFH Facilities determinants on improving WFH performance was identified. Two hypotheses, i) Work-Related Family, and ii) Modern Technology had a significant relationshipwithWFH performance. Besides, four hypotheses were not supported and had no significant relationshipwithWFH performance (based on the current situation). Therefore, it is recommended for any organisations that preferring to implement WFH as an effective solution during the pandemic situation to use this WFH Facilities model that focuses on both factors Work-Family Related and Modern Technology.As this research was exploratory, it is proposed that for future research, a longitudinal research methodology should be used.

\section{Acknowledgement}

This research is sponsored under GeranAnugerahAkademikUniversiti. The authors would like to express their deepest gratitude to UniversitiTeknologi MARA, Cawangan Perak.

\section{References}

1. Ahmadi, M., Helms, M. M., \& Ross, T. J. (2000). Technological developments: Shaping the telecommuting work environment of the future. Facilities, 18, 83-89. https://doi.org/10.1108/02632770010312204

2. Ajzen, I. (2001). Nature and Operation of Attitudes. Annual Review of Psychology, 52(1), 27-58. https://doi.org/10.1146/annurev.psych.52.1.27

3. Akbar, M. F., Akbar, M., \&Mukhtar, M. (2019).The Effect of Supervision, Work Culture, and Trust to the Performance of Elementary Public-School Principal of West Jakarta City.35-40. https://doi.org/10.2991/picema-18.2019.7 
4. Al Ghayab, H. R., Li, Y., Abdulla, S., Diykh, M., \& Wan, X. (2016).Classification of epileptic EEG signals based on simple random sampling and sequential feature selection.Brain Informatics, 3. https://doi.org/10.1007/s40708-016-0039-1

5. Ali, I. M., Zaidi, M. A., Ismail, K., \&Ariff, M. I. M. (2019).Influences of Knowledge Sharing in Improving Facilities Management Performance of Private Finance Initiative Projects. International Journal of Academic Research in Business and Social Sciences, 9(2), 971-988. https://doi.org/10.6007/IJARBSS/v9-i2/5655

6. Azlan, A. A., Hamzah, M. R., Sern, T. J., Ayub, S. H., \& Mohamad, E. (2020). Public knowledge, attitudes and practices towards COVID-19: A cross-sectional study in Malaysia. PLOS ONE, 15(5), e0233668. https://doi.org/10.1371/journal.pone.0233668

7. Bedford, J., Enria, D., Giesecke, J., Heymann, D. L., Ihekweazu, C., Kobinger, G., Lane, H. C., Memish, Z., Oh, M. don, Sall, A. A., Schuchat, A., Ungchusak, K., \&Wieler, L. H. (2020). COVID-19: towards controlling of a pandemic. In The Lancet (Vol. 395, Issue 10229, pp. 1015-1018). Lancet Publishing Group. https://doi.org/10.1016/S0140-6736(20)30673-5

8. Beliaeva, L., \&Chernyavskaya, V. (2019).Technical writer in the framework of modern natural language processing tasks. Journal of Siberian Federal University - Humanities and Social Sciences, 12(1), 20-31. https://doi.org/10.17516/1997-1370-0377

9. Berthon, P. R., Pitt, L. F., Plangger, K., \& Shapiro, D. (2012). Marketing meets Web 2.0, social media, and creative consumers: Implications for international marketing strategy. Business Horizons, 55(3), 261-271. https://doi.org/10.1016/j.bushor.2012.01.007

10. Bloom, N., Liang, J., Roberts, J., \& Ying, Z. J. (2015). Does working from home work? Evidence from a chinese experiment. Quarterly Journal of Economics, 130(1), 165-218. https://doi.org/10.1093/qje/qju032

11. Brynjolfsson, E., Horton, J., Ozimek, A., Rock, D., Sharma, G., \&TuYe, H.-Y. (2020). COVID-19 and Remote Work: An Early Look at US Data. In National Bureau of Economic Research (No. 27344). https://doi.org/10.3386/w27344

12. Chin, W. W. (1998). Commentary: Issues and Opinion on Structural Equation Modeling. In MIS Quarterly (Vol. 22).Management Information Systems Research Center, University of Minnesota. https://doi.org/10.2307/249674

13. De Spiegelaere, S., Van Gyes, G., \& Van Hootegem, G. (2016). Not All Autonomy is the Same. Different Dimensions of Job Autonomy and Their Relation to Work Engagement \&amp; Innovative Work Behavior. Human Factors and Ergonomics in Manufacturing \& Service Industries, 26(4), 515527. https://doi.org/10.1002/hfm.20666

14. Deng, Z., Morissette, R., \&Messacar, D. (2020).Running the economy remotely: potential for working from home during and after COVID-19. NCVER's International Tertiary Education Research Database.

15. Eisenberger, R., Lynch, P., Aselage, J., \&Rohdieck, S. (2004). Who takes the most revenge? Individual differences in negative reciprocity norm endorsement. Personality and Social Psychology Bulletin, 30(6), 787-799. https://doi.org/10.1177/0146167204264047

16. F. Hair Jr, J., Sarstedt, M., Hopkins, L., \& G. Kuppelwieser, V. (2014). Partial least squares structural equation modeling (PLS-SEM). European Business Review, 26(2), 106-121. https://doi.org/10.1108/EBR-10-2013-0128

17. Gao, A., \& Jiang, J. (2019). Perceived Empowering Leadership, Harmonious Passion, and Employee Voice: The Moderating Role of Job Autonomy.Frontiers in Psychology, 10(JULY), 1484. https://doi.org/10.3389/fpsyg.2019.01484

18. Grzywacz, J. G., \& Carlson, D. S. (2007). Conceptualizing Work-Family Balance: Implications for Practice and Research. Advances in Developing Human Resources, 9(4), 455-471. https://doi.org/10.1177/1523422307305487

19. Gupta, S., \&Shabbir, J. (2008). On improvement in estimating the population mean in simple random sampling. Journal of Applied Statistics, 35(5), 559-566. https://doi.org/10.1080/02664760701835839

20. Hair, J. F., Black, W. C., Babin, B. J., \& Anderson, R. E. (2010).Multivariate Data Analysis. Pearson.

21. Halcomb, E., Williams, A., Ashley, C., McInnes, S., Stephen, C., Calma, K., \& James, S. (2020). The support needs of Australian primary health care nurses during the COVID-19 pandemic. Journal of Nursing Management, 28(7), 1553-1560. https://doi.org/10.1111/jonm.13108

22. Hassanain, M. A. (2006). Factors affecting the development of flexible workplace facilities.In Journal of Corporate Real Estate (Vol. 8, Issue 4, pp. 213-220). https://doi.org/10.1108/14630010610714880

23. Henseler, J., Hubona, G., \& Ray, P. A. (2016).Using PLS path modeling in new technology research: updated guidelines. Industrial Management \& Data Systems, 116(1), 2-20. https://doi.org/10.1108/IMDS-09-2015-0382 
24. Khoshnaw, S., \&Alavi, H. (2020). Examining the Interrelation Between Job Autonomy and Job Performance: A Critical Literature Review. Multidisciplinary Aspects of Production Engineering, 3(1), 606-616. https://doi.org/10.2478/mape-2020-0051

25. Kojo, I. V. I., \&Nenonen, S. (2015). Places for multi - locational work-opportunities for facilities management. Facilities, 33, 20-37. https://doi.org/10.1108/F-05-2013-0043

26. Kraemer, M. U. G., Yang, C. H., Gutierrez, B., Wu, C. H., Klein, B., Pigott, D. M., du Plessis, L., Faria, N. R., Li, R., Hanage, W. P., Brownstein, J. S., Layan, M., Vespignani, A., Tian, H., Dye, C., Pybus, O. G., \&Scarpino, S. V. (2020). The effect of human mobility and control measures on the COVID-19 epidemic in China. Science, 368(6490), 493-497. https://doi.org/10.1126/science.abb4218

27. Kumar, A., Gupta, P. K., \&Srivastava, A. (2020).A review of modern technologies for tackling COVID19 pandemic. Diabetes and Metabolic Syndrome: Clinical Research and Reviews, 14(4), 569-573. https://doi.org/10.1016/j.dsx.2020.05.008

28. Li, L., Zhang, Q., Wang, X., Zhang, J., Wang, T., Gao, T. L., Duan, W., Tsoi, K. K. F., \& Wang, F. Y. (2020). Characterizing the Propagation of Situational Information in Social Media during COVID-19 Epidemic: A Case Study on Weibo. IEEE Transactions on Computational Social Systems, 7(2), 556562. https://doi.org/10.1109/TCSS.2020.2980007

29. Loehlin, J. C. (1998). Latent variable models: An introduction to factor, path, and structural analysis. Lawrence Erlbaum Associates Publishers. http://psycnet.apa.org/record/1998-07069-000

30. Montenovo, L., Jiang, X., Rojas, F. L., Schmutte, I., Simon, K., Weinberg, B., \& Wing, C. (2020).Determinants of Disparities in Covid-19 Job Losses.In National Bureau of Economic Research (No. 27132). https://doi.org/10.3386/w27132

31. Noor, N. M. (2003). Work- and family-related variables, work-family conflict and women's well-being: Some observations. Community, Work and Family, 6(3), 297-319. https://doi.org/10.1080/1366880032000143474

32. Raja, R., \&Nagasubramani, P. C. (2018).Impact of modern technology in education.Journal of Applied and Advanced Research, 3(S1), 33. https://doi.org/10.21839/jaar.2018.v3is1.165

33. Robertson, K. (2000). Work transformation: Integrating people, space and technology. Facilities, 18, 376-382. https://doi.org/10.1108/02632770010349600

34. Satardien, M., Jano, R., \&Mahembe, B. (2019).The relationship between perceived organisational support, organisational commitment and turnover intention among employees in a selected organisation in the aviation industry.South African Journal of Childhood Education, 17. https://doi.org/10.4102/sajhrm.v17i0.1123

35. Shah, K., Kamrai, D., Mekala, H., Mann, B., Desai, K., \& Patel, R. S. (2020). Focus on Mental Health During the Coronavirus (COVID-19) Pandemic: Applying Learnings from the Past Outbreaks. Cureus, 12(3). https://doi.org/10.7759/cureus.7405

36. Velavan, T. P., \& Meyer, C. G. (2020).The COVID-19 epidemic. Tropical Medicine and International Health, 25(3), 278-280. https://doi.org/10.1111/tmi.13383

37. Wang, Z., \& Kim, H. G. (2017). Can Social Media Marketing Improve Customer Relationship Capabilities and Firm Performance? Dynamic Capability Perspective. Journal of Interactive Marketing, 39, 15-26. https://doi.org/10.1016/j.intmar.2017.02.004

38. WHO. (2020). Infection prevention and control during health care when novel coronavirus (nCoV) infection is suspected. https://www.who.int/publications/i/item/infection-prevention-and-control-duringhealth-care-when-novel-coronavirus-(ncov)-infection-is-suspected-20200125 